\title{
THE LEGAL NATURE OF NATURAL OBLIGATIONS
}

\author{
Davud A. Davudov \\ Volgograd State University, Volgograd, Russian Federation
}

\begin{abstract}
Introduction: the paper discusses the approaches to understanding the legal force of natural obligations. The author comes to the conclusion that the problem of regulating natural obligations in modern Russian civil law is complicated by the lack of legal fixation of such obligations. The analysis of the approaches of the civil scientists has shown that there is a unanimous opinion among the scientists about the need to recognize natural obligations as an integral element of the system of obligations in Russian civil law. The purpose of the work is to study the reasons for the creation of natural obligations, as well as their legal nature and settlement procedure. Methods: the methodological framework for the study is a set of methods of scientific knowledge, among which the main ones are the method of analysis and the formal logical method. Results: the approaches to understanding natural obligations in foreign and domestic civil law are studied and the prospects for legal registration of this type of obligations are revealed. Conclusions: due to their nature, natural obligations have not been enshrined in the legal documents for a long time, which has caused complications in protecting the creditors' rights.
\end{abstract}

Key words: legal nature, obligation, natural obligation, obligation system, creditors.

Citation. Davudov D.A. The Legal Nature of Natural Obligations. Legal Concept, 2020, vol. 19, no. 1, pp. 102-107. (in Russian). DOI: https://doi.org/10.15688/lc.jvolsu.2020.1.14

УДК 347.4

ББК 67.404.219
Дата поступления статьи: 10.01.2020

Дата принятия статьи: 29.01.2020

\section{ПРАВОВАЯ ПРИРОДА НАТУРАЛЬНЫХ ОБЯЗАТЕЛЬСТВ}

\author{
Давуд Ахмедович Давудов \\ Волгоградский государственный университет, г. Волгоград, Российская Федерация
}

\begin{abstract}
Введение: в статье рассматриваются подходы к пониманию юридической силы натуральных обязательств. Автор приходит к выводу, что проблема регулирования натуральных обязательств в современном российском гражданском праве осложняется отсутствием юридической фиксации подобного рода обязательств. Анализ подходов ученых-цивилистов показал, что среди ученых существует единодушное мнение о необходимости признания натуральных обязательств неотъемлемым элементом системы обязательств в российском гражданском праве. Цель настоящей работы: изучить основания возникновения натуральных обязательств, а также их правовую природу и порядок урегулирования. Методы: методологическую основу проведенного исследования составляет совокупность методов научного познания, среди которых основное место занимают метод анализа и формально-логический метод. Результаты: изучены подходы к пониманию натуральных обязательств в зарубежной и отечественной цивилистике и выявлены перспективы юридического оформления данного вида обязательств. Выводы: в силу своей естественной природы натуральные 으 обязательства на протяжении долгого времени не закреплялись в правовых документах, что стало причиной خे осложнения защиты прав кредиторов.

¿ Ключевые слова: правовая природа, обязательство, натуральное обязательство, система обязательств, க் кредиторы.

Цитирование. Давудов Д. А. Правовая природа натуральных обязательств // Legal Concept = Правовая парадигма.-2020. - T. 19, № 1. -C. 102-107. -DOI: https://doi.org/10.15688/lc.jvolsu.2020.1.14
\end{abstract}




\section{Введение}

Проблема понимания юридической силы натуральных обязательств является одним из основных дискуссионных вопросов гражданского права. Возникновение разных подходов к пониманию натурального обязательства связано с различиями в определении объекта данного обязательства: с одной стороны, оно понимается как правовая форма перемещения имущественных или неимущественных благ в процессе товарообмена [1], с другой стороны, - это возможность воздействовать в рамках права на волевую сферу контрагента и понуждать его к исполнению действий, выгодных для кредитора или третьего лица. То есть объектом обязательства воспринимается или вещь, или личность должника [5]. $\mathrm{C}$ точки зрения понимания юридической силы натурального обязательства наиболее важным представляется исследование волевого основания возникновения таких обязательств.

\section{Подходы к пониманию природы натуральных обязательств}

В настоящее время большинство исследователей вопроса о натуральных обязательствах сходятся во мнении, что необеспеченность натурального обязательства исковыми требованиями является важным, но не единственным признаком, определяющим правовую природу исследуемого феномена [7, с. 105].

Подобная позиция в понимании сущности натурального обязательства выработалась под влиянием римского права, в котором обязанность лица неразрывно связывалась с возможностью судебного принуждения к ее исполнению (иском) [10]. Как справедливо отмечал Ю.С. Гамбаров, «современное представление о праве считает иск не основанием, а последствием права и в большинстве случаев придатком к нему. Право существует и до того, чем оно воплощается в иск, и существует в силу абстрактной нормы, а не только своей судебной защиты в данном конкретном случае» [4].

Для римского права было характерно признание обязательством только того отношения, которое закреплялось в нормах объек- тивного права и, тем самым, признавалось государством, в том числе в качестве объекта судебной защиты [9]. В этом случае современные обязательственные правоотношения, то есть волевые акты субъектов, направленные на возникновение, изменение и прекращение прав и обязанностей, но не поименованные в законодательстве, не наделялись бы исковой защитой и попадали в разряд натуральных.

Следовательно, в римском праве «любое обязательственное отношение считалось отношением фактическим, а не правоотношением, и только после обращения в суд это отношение становилось защищаемым иском легальным правоотношением» [2]. Вместе с тем действующий ГК РФ предусматривает двенадцать способов несудебной защиты гражданских прав. Согласимся, что приоритетным является судебный способ защиты нарушенных гражданских прав, тем не менее, он не абсолютизируется и его наличие не детерминирует существование права. Кроме того, существуют и неисковые судебные способы защиты нарушенных прав.

По нашему мнению, в качестве признака, определяющего юридическую сущность натурального обязательства, помимо отсутствия исковой защищенности, следует рассматривать невозможность требования лицом, исполнившим натуральное обязательство, исполненного обратно. Именно это свойство, на наш взгляд, раскрывает сущность натурального обязательства, как признаваемого правом, но не защищаемого судом требования. В противном случае, если натуральное обязательство не имеет судебной защиты и не признано законом, исполненное по нему могло быть возвращено, по аналогии с недействительной сделкой.

Подобное понимание натурального обязательства отвечает диспозитивному характеру современного российского гражданского права, в котором, как известно, обязательства регулируются на основании принципов свободы субъектов в установлении своих прав и обязанностей на основе договора и в определении любых не противоречащих законодательству условий договора.

Таким образом, в российском гражданском законодательстве следует признать как 
возможность возникновения, так и существования натуральных обязательств. Тем не менее в действующем ГК РФ натуральные обязательства не поименованы, поэтому возникает необходимость определения их внутривидовых связей в рамках обязательств, регулируемых законом [12].

Наиболее известной классификацией обязательств, из существующих в современной российской цивилистике, следует признать систему, предложенную О.С. Иоффе. Ученый отмечал: «Система обязательств, полностью соответствующая задаче их надлежащего изучения, может быть построена лишь на основе использования комбинированного класссификационного критерия, соединяющего экономические и соответствующие юридические признаки» [6, с. 24].

В соответствии с выдвинутым О.С. Иоффе тезисом, основанием для построения системы обязательств выступает экономический и юридический результат, который преследовали участники обязательственного правоотношения [13]. Очевидно, что система носит исключительно прикладной характер и не включает в себя такие классификации обязательств, как обязательства с множественностью лиц, обязательства альтернативные и факультативные, возмездные и безвозмездные. Натуральные обязательства в современном контексте не могут быть отнесены ни к одной из предложенных О.С. Иоффе категорий, поскольку представляют собой более высокий уровень систематизации или абстрактности [14].

Примечательным является взгляд на видовую принадлежность натуральных обязательств, изложенный П.С. Тарабаевым в статье «О категории натуральных (неденежных) обязательств в гражданском обороте» [6]. Автор, поддерживая точку зрения М.М. Агаркова, отрицает наличие в отечественном гражданском праве натуральных обязательств, поскольку «государственное принуждение, выраженное в возможности применения санкций, является необходимым атрибутом любого гражданско-правового обязательства. Без обеспечения государственным принуждением обязательственная правовая связь превращается в некую фикцию» [6, с. 34].
В связи с этим П.С. Тарабаев предлагает включить натуральные обязательства в категорию недежных, то есть таких обязательств, в которых встречное предоставление не исчисляется в денежном эквиваленте. Таким образом, к категории натуральных обязательств, по мнению исследователя, относятся деликтные, кондикционные, безвозмездные, пассивные и обязательства по выполнению работ и услуг.

Несмотря на давнюю историю и наличие норм о натуральных обязательствах в актах гражданского законодательства государств с общепризнанными частноправовыми традициями, таких как Франция или Нидерланды, взгляды на юридическую сущность натурального обязательства практически не меняются. Традиционно под ним понимается обязательство, не обеспеченное исковыми требованиями.

Наличие неденежных обязательств в гражданском законодательстве очевидно. Существуют безвозмездные договоры, договоры мены, обещание дарения, но в натуральных обязательствах, как было показано выше, товарообменный характер неглавный признак, и поэтому нельзя отрицать существования возмездных или денежных натуральных обязательств. Однако натуральный характер обязательства в системе его качественных характеристик стоит выше, чем возмездность или безвозмездность.

\section{Законодательное закрепление натуральных обязательств в современном российском праве}

В 2008 г. по инициативе Д.А. Медведева была разработана Концепция развития гражданского законодательства (далее - Концепция) [8], положения которой предполагалось внести в действующий Гражданский кодекс Российской Федерации в качестве изменений. Работа над новеллами была поручена именитым российским юристам, представителям научного сообщества, адвокатуры, судейского корпуса, и велась по пяти направлениям.

Реформированию, по замыслу участников подготовки Концепции, должны были подвергнуться те подотрасли гражданского права, которые существовали в неизменном виде 
с момента принятия Гражданского кодекса Российской Федерации (далее - ГК РФ). В связи с четко определенным объектом исследования и его ограниченным объемом, нам представляется нецелесообразным углубляться в исследование истории разработки Концепции. Процесс достаточно подробно описан в интервью В.Ф. Яковлева «Концепция развития гражданского законодательства», данном им справочно-правовой системе «Гарант», в интервью Е.А. Суханова «Перспективы развития гражданского законодательства в России: планы и современные реалии» и в беседе В.В. Витрянского с корреспондентом газеты «ЭЖ-Юрист».

Видные российские цивилисты сходятся во мнении, что ГК РФ создавался в качестве правового акта переходного к рыночной экономике периода [11]. Кодекс создавался, по словам Е.А. Суханова, иногда интуитивно, тем не менее, закон вобрал в себя наиболее передовые цивилистические концепции европейских стран, разработки российских юристов и опыт законодательства прошлых лет, не противоречащий либеральным принципам частного права [5].

Тщательная работа лучших отечественных юристов позволила новому кодексу не только эффективно регулировать процесс становления российского рынка, но и в течение последующих почти двух десятилетий быть «экономической конституцией» России.

Вместе с тем постоянно развивающиеся экономические отношения требуют новых правовых форм, закрепление которых необходимо в нормах гражданского законодательства. Именно поэтому потребовалось совершенствование наиболее востребованных в имущественном обороте подотраслей гражданского права - вещного права и обязательственного.

Создатели Концепции поставили перед собой задачу внести ясность во многие концептуальные положения гражданского права. Так, предлагается исключить из кодекса все нормы, которые допускают регулирование отношений, не входящих в предмет гражданского права, например, земельных правоотношений. Текст Концепции и проект ГК РФ содержат большее количество принципов гражданского права по сравнению с действующей редакцией гражданского кодекса. В частности, в проект внесен принцип добросовестности участников гражданских правоотношений.

В раздел об обязательственном праве включено уточненное определение обязательства, дополненное указанием на синаллагматический (взаимный) характер прав и обязанностей сторон. По мнению В.В. Витрянского, существующая формулировка обязательства, как обязанность должника совершить или воздержаться от совершения определенных действий в пользу кредитора, отражает самые простейшие правоотношения, характерные только для деликтных и кондикционных обязательств. В свою очередь, большинство обязательств, регулируемых ГК РФ, являются договорными и носят характер как раз взаимных [4].

Раздел Концепции «Обязательственное право», по замыслу разработчиков, должен будет пополниться нормами об альтернативных и факультативных обязательствах, а также статьями о натуральных обязательствах. Подобное дополнение Гражданского кодекса позволит разрешить такие практические вопросы, как определение возможных оснований возникновения такого рода обязательств: могут ли стороны договора своим волеизъявлением превратить договорное обязательство в натуральное или это является прерогативой законодателя. Допустима ли обратная ситуация, когда по соглашению сторон натуральному обязательству придается статус обычного обязательства. Подлежит ли в данном случае требование кредитора судебной защите.

\section{СПИСОК ЛИТЕРАТУРЫ}

1. Алфиренко, О. А. Натуральные обязательства в российском гражданском праве: тенденции развития и значение для практики / О. А. Алфиренко, С. А. Кирокосян // Проблемы и перспективы юриспруденции в современных условиях : сб. науч. тр. по итогам Междунар. науч.-практ. конф. - Казань, 2014. - 56 с.

2. Витрянский, В. В. Некоторые основные положения Концепции развития гражданского законодательства Российской Федерации об обязательствах / В. В. Витрянский // Журнал российского права. -2010 . - № 1 .

3. Витрянский, В. В. Обязательственная реформа / В. В. Витрянский // ЭЖ-Юрист. - 2009. - № 15. 
4. Гамбаров, Ю. С. Гражданское право. Общая часть / Ю. С. Гамбаров. - М. : Зерцало, 2003. $-816 \mathrm{c}$.

5. Епифанов, А. Е. К вопросу о влиянии международного права на формирование механизмов защиты прав и свобод человека (вопросы теории и истории) / А. Е. Епифанов // Вестник Южно-Уральского государственного университета. - 2015. - Т. 15, № 2. - C. 14-21.

6. Иоффе, О. С. Обязательственное право / О. С. Иоффе. - М. : Юрид. лит., 1975. - 880 с.

7. Мертвищев, А. В. Натуральные обязательства в российском гражданском праве / А. В. Мертвищев. - М. : Проспект, 2015. - 200 с.

8. Проект Федерального закона № 47538-6 «О внесении изменений в части первую, вторую, третью и четвертую Гражданского кодекса Российской Федерации, а также в отдельные законодательные акты Российской Федерации». - Электрон. текстовые дан. - Режим доступа: http://www. consultant.ru/law/hotdocs/11059.html/ (дата обращения: 01.11.2019). - Загл. с экрана.

9. Федотов, А. Г. Натуральные обязательства / А. Г. Федотов // Вестник гражданского права. 2010. - № 1 .

10. Хвостов, В. М. Натуральные обязательства по римскому праву / В. М. Хвостов. - М. : Унив. тип., 1898. -516 с.

11. Щенникова, Л. В. Натуральные обязательства в гражданском праве Российской Федерации: истоки, современное состояние и перспективы развития / Л. В. Щенникова // Законодательство. Право для бизнеса. - 2007. - № 11. - С. 9-17.

12. Amendments to the Civil Code of the Russian Federation: Contradictions of Theory and Practice / A. O. Inshakova, A. I. Goncharov, O. A. Mineev and M. V. Sevostyanov // Contributions to Economics. Russia and the European Union: Development and Perspectives Number XIII. - 2017. - P. 147-153.

13. Inshakova, A. O. Institutional Ambiguity of Regulation of Possessory Relations in Modern Russia / A. O. Inshakova, A. I. Goncharov, M. V. Sevostyanov // Overcoming Uncertainty of Institutional Environment as a Tool of Global Crisis Management. 2017. - Edition Number 1. - P. 207-212.

14. Inshakova, A. O. Securities as a Subject of Financial and Economic Interest and Object of Civil Law Relations / A. O. Inshakova, A. I. Goncharov // Pravo-Zhurnal vysshei shkoly ekonomiki. - 2017. № 4. - P. 97-110.

\section{REFERENCES}

1. Alfirenko O.A., Kirokosyan S.A. Naturalnyye obyazatelstva $\mathrm{v}$ rossiyskom grazhdanskom prave: tendentsii razvitiya i znacheniye dlya praktiki [Natural Obligations in Russian Civil Law: Development Trends and Significance for Practice]. Problemy i perspektivy yurisprudentsii v sovremennykh usloviyakh: sb. nauch. tr. po itogam Mezhdunar. nauch.-prakt. konf. [Problems and Prospects of Law in Modern Conditions: Collection of Scientific Works]. Kazan, 2014.56 p.

2. Vitryanskiy V.V. Nekotoryye osnovnyye polozheniya Kontseptsii razvitiya grazhdanskogo zakonodatelstva Rossiyskoy Federatsii ob obyazatelstvakh [Some Basic Provisions of the Concept of Development of Civil Legislation of the Russian Federation on Obligations]. Zhurnal rossiyskogo prava [Journal of Russian Law], 2010, no. 1.

3. Vitryanskiy V.V. Obyazatelstvennaya reforma [Mandatory Reform]. EZh-Yurist, 2009, no. 15.

4. Gambarov Yu.S. Grazhdanskoye pravo. Obshchaya chast [Civil Law. General Part]. Moscow, Zertsalo Publ., 2003. 816 p.

5. Epifanov A.E. K voprosu o vliyanii mezhdunarodnogo prava na formirovaniye mekhanizmov zashchity prav i svobod cheloveka (voprosy teorii i istorii) [On the Impact of International Law on the Formation of Mechanisms for the Protection of Human Rights and Freedoms (Questions of Theory and History)]. Vestnik Yuzhno-Uralskogo gosudarstvennogo universiteta [Bulletin of the South Ural State University], 2015, vol. 15, no. 2, pp. 14-21.

6. Ioffe O.S. Obyazatelstvennoye pravo [Law of Obligations]. Moscow, Yuridicheskaya literatura Publ., $1975.880 \mathrm{p}$.

7. Mertvishchev A.V. Naturalnyye obyazatelstva $v$ rossiyskom grazhdanskom prave [Natural Obligations in Russian Civil Law]. Moscow, Prospekt Publ., 2015. 200 p.

8. Proekt Federalnogo zakona № 47538-6 "O vnesenii izmeneniy v chasti pervuyu. vtoruyu. tretyu i chetvertuyu Grazhdanskogo kodeksa Rossiyskoy Federatsii. a takzhe v otdelnyye zakonodatelnyye akty Rossiyskoy Federatsii» [Draft Federal Law No. 47538-6 "On Amendments to Parts One, Two, Three and Four of the Civil Code of the Russian Federation, as Well as to Certain Legislative Acts of the Russian Federation"]. URL: http:// www. consultant.ru/law/hotdocs/11059.html/ (accessed 1 November 2019).

9. Fedotov A.G. Naturalnyye obyazatelstva [Natural Obligations]. Vestnik grazhdanskogo prava [Bulletin of Civil Law], 2010, no. 1.

10. Khvostov V.M. Naturalnyye obyazatelstva po rimskomu pravu [Natural Obligations Under Roman Law]. Moscow, Univ. tip., 1898. 516 p.

11. Shchennikova L.V. Naturalnyye obyazatelstva v grazhdanskom prave Rossiyskoy Federatsii: istoki. sovremennoye sostoyaniye i perspektivy razvitiya 
[Natural Obligations in the Civil Law of the Russian Federation: Origins, Current State and Prospects of Development]. Zakonodatelstvo. Pravo dlya biznesa [Legislation. Law for Business], 2007, no. 11, pp. 9-17.

12. Inshakova A.O., Goncharov A.I., Mineev O.A., Sevostyanov M.V. Amendments to the Civil Code of the Russian Federation: Contradictions of Theory and Practice. Contributions to Economics. Russia and the European Union: Development and Perspectives Number XIII, 2017, pp. 147-153.
13. Inshakova A.O., Goncharov A.I., Sevostyanov M.V. Institutional Ambiguity of Regulation of Possessory Relations in Modern Russia. Overcoming Uncertainty of Institutional Environment as a Tool of Global Crisis Management, 2017, Edition Number 1, pp. 207-212.

14. Inshakova A.O., Goncharov A.I. Securities as a Subject of Financial and Economic Interest and Object of Civil Law Relations. Pravo-Zhurnal vysshei shkoly ekonomiki, 2017, no. 4, pp. 97-110.

\section{Information About the Author}

Davud A. Davudov, Candidate of Sciences (Jurisprudence), Associate Professor, Department of Civil and International Private Law, Volgograd State University, Prosp. Universitetsky, 100, 400062 Volgograd, Russian Federation, dav0587@mail.ru, https://orcid.org/0000-0002-1706-6124

\section{Информация об авторе}

Давуд Ахмедович Давудов, кандидат юридических наук, доцент кафедры гражданского и международного частного права, Волгоградский государственный университет, просп. Университетский, 100, 400062 г. Волгоград, Российская Федерация, dav0587@mail.ru, https://orcid.org/0000-0002-1706-6124 